\title{
PENDUGAAN EROSI PADA DAERAH ALIRAN SUNGAI (DAS) PRAFI KABUPATEN MANOKWARI
}

\section{(Erosion Predicted Approach of the Prafi Watershed area in Manokwari)}

\author{
Budi Suryanajaya $^{1}$, E.M. Kesaulija ${ }^{1}$ dan Surianto Bataradewa ${ }^{2 凶}$ \\ ${ }^{1}$ Jurusan Kehutanan, Fakultas Kehutanan Universitas Papua Manokwari, Papua Barat, \\ 98314. Tlp/Fax: +62986211065. \\ ${ }^{2}$ Jurusan Matematika, Fakultas Matematika dan Ilmu Pengetahuan Alam Universitas Papua \\ Manokwari, Papua Barat, 98314. Tlp/Fax: +62986211065 \\ Penulis Korespondensi: Email: s.bataradewa@unipa..ac.id \\ Diterima: 10 Jan 2017| Disetujui: 26 Feb 2017
}

\begin{abstract}
Abstrak
Daerah aliran sungai memegang peranan penting dalam menjaga daya dukung kawasan yang salah satunya berperan dalam mencegah erosi. Penelitian ini bertujuan untuk menduga besarnya erosi yang terjadi pada saat sekarang di DAS Prafi sehingga dapat menjadi sumber informasi awal bagi pengambil kebijakan dan pengelolaannya. Guna menduga besarnya erosi digunakan metoda overlay yaitu beberapa peta transparan dengan kombinasi data/survey lapangan dan analisis tanah. Selain itu beberapa analisis indeks erosivitas hujan, erodibilitas, dan analisis faktor panjang dan kemiringan lereng juga dikerjakan guna mendapatakan keakuratan informasi pendugaan erosi. Hasil penelitian menunjukkan bahwa indeks erosivitas hujan maksimum terjadi pada bulan Maret (190,74 ton.m/ha.jam), sementara minimum terjadi pada bulan Oktober (51,93 ton.m/ha.jam). Indeks kepekaan tanah berlihat cukup variatif pada beberapa lokasi. Tersedianya kawasan hutan dengan tipe vegetas hutan yang beragam dapat meminimalisir potensi erosi pada DAS Prafi.
\end{abstract}

Kata kunci: Daerah aliran sungai, erosi, pemanfaatan lahan, Prafi.

\begin{abstract}
Watershed area has been fundamental in managing and supporting surrounding land and ecosystem of which one of the pivotal roles was to prevent erosion. The objective of this study was to predict how far the erosion and its current condition of erosion in Prafi watershed area. In order to understand how big the erosion effect, overlay method by way of combining several based condition maps and field based survey and soil analysis were carried out. In addition, rainfall erosive index, erodibility, and analysis of slope were undertaken to obtain more inclusive result. The result indicated that the maximum rainfall erocovity index was accurred in March (190.74 ton.m/ha.hour), while the minimum has been occurred in October (51.93 ton.m/ha.hour). The soil sensitivity index was quite various in several study sites. Forest availability coupled with a balanced ecosystem were turned out to be a pivotal indicator to minimize the potency of erosion of Prafi watershed.
\end{abstract} Keywords: Watershed, erosion, land utilization, Prafi 


\section{PENDAHULUAN}

Daerah aliran sungai (DAS) sebagai suatu ekosistem biasanya dibagi menjadi daerah hulu, tengah dan hilir. Ekosistem DAS hulu merupakan bagian yang penting karena mempunyai fungsi perlindungan terhadap seluruh bagian DAS. Perlindungan ini antara lain, dari segi fungsi tata air. Adanya aktifitas terhadap perubahan landskap termasuk perubahan tata guna lahan yang dilaksanakan di daerah hulu DAS tidak hanya memberikan dampak di daerah dimana kegiatan tersebut berlangsung, tetapi juga akan menimbulkan dampak di daerah hilir seperti terjadinya perubahan fluktuasi debit dan transpor sedimen serta material terlarut dalam sistem aliran air. Salah satu dampaknya adalah terjadinya erosi di daerah hulu karena praktek bercocok tanam yang tidak mengikuti kaidah-kaidah konservasi tanah dan air, tidak hanya memberikan dampak di daerah dimana erosi itu terjadi, tetapi juga akan menimbulkan dampak di daerah hilir dalam bentuk terjadinya sedimentasi sehingga mengakibatkan penurunan kapasitas tampung atau pendangkalan waduk dan sungai, bahkan dapat mengakibatkan banjir di daerah hilir (Fuady dan Azizah 2008).

Daerah aliran sungai mempunyai karakteristik yang spesifik seperti tanah, tataguna lahan, topografi serta kelerengan dalam merespon curah hujan yang jatuh di dalam wilayah DAS tersebut. Hujan yang jatuh dapat memberikan pengaruh terhadap besar kecilnya evapotranspirasi, infiltrasi, perkolasi, air larian, aliran permukaan, kandungan air tanah dan aliran sungai. Di antara faktor-faktor yang berperan dalam menentukan sistem DAS, faktor tataguna lahan dan kelerengan dapat direkayasa oleh manusia, faktorfaktor yang lain bersifat alamiah, oleh karenanya tidak di bawah kontrol manusia. Dengan demikian, dalam merencanakan suatu pengelolaan daerah aliran sungai, perubahan tataguna lahan dan kemiringan serta panjang lereng harus menjadi salah satu focus perhatian (Muharomah 2014).

Degradasi lingkungan yang terjadi pada DAS akhir-akhir ini berpangkal pada pertumbuhan manusia yang cepat mengakibatkan perbandingan antara jumlah penduduk dan lahan pertanian tidak seimbang (Wuryanti dan Susanti 2015). Hal ini menyebabkan pemilikan lahan pertanian menjadi semakin sempit. Keadaan tersebut seringkali mendorong petani untuk merambah hutan dan lahan tidak produktif lainnya sebagai lahan pertanian. Lahan yang kebanyakan marjinal apabila diusahakan dengan caracara yang mengabaikan kaidah-kaidah konservasi tanah rentan terhadap erosi dan longsor. Meningkatnya erosi dan longsor di daerah tangkapan air akan meningkatkan muatan sedimen sungai pada daerah hilir. Demikian juga perambahan hutan menyebabkan hilangnya serasah dan humus yang dapat menyerap air hujan sehingga menyebabkan meningkatnya koefisien air larian yaitu meningkatkan jumlah air hujan yang menjadi air larian dan dengan demikian meningkatkan debit sungai (Laturua dkk, 2018). Dalam skala besar, kejadian tersebut akan mengganggu perilaku aliran sungai, pada musim hujan debit air sungai meningkat tajam, sementara pada musim kemarau debit air sangat rendah. Dengan demikian, resiko banjir pada musim hujan dan kekeringan pada musim kemarau meningkat. 
Daerah Aliran Sungai (DAS) Prafi merupakan DAS Prioritas yang memiliki nilai hidrologis, ekonomis dan sosial yang relatif tinggi bagi kelangsungan hidup masyarakat di wilayah Manokwari, khususnya pada Distrik Prafi dan Distrik Warmare. Kondisi DAS Prafi meliputi keadaan lereng dan ketinggian absolut, yaitu : daerah landai sampai curam. Kemiringan lereng akan memiliki pengaruh terhadap kecepatan dan volume limpasan permukaan. Kondisi topografi DAS Prafi sangat bervariasi mulai dari dataran sampai pegunungan.

Dengan kondisi topografi yang ada di DAS Prafi dan seiring dengan bertambahnya jumlah penduduk di sekitar DAS Prafi, berdampak pada perubahan kondisi lahan untuk pemenuhan kebutuhan hidup di sekitar DAS. Perubahan kondisi ini jika dibiarkan berlanjut akan mengakibatkan ketidakmampuan suatu lahan untuk menahan atau menekan laju aliran permukaan pada saat musim penghujan dan akan berpotensi besar terjadinya erosi. Untuk daerah DAS Prafi, khususnya daerah-daerah penggunungan yang berdekatan dengan sungai-sungai, vegetasi yang ada disekitarnya sudah mulai berkurang, karena banyak perubahan kondisi lahan terutama untuk perkebunan masyarakat.

Penelitian ini bertujuan untuk menduga besarnya erosi yang terjadi pada saat sekarang pada DAS Prafi. Kegunaan penelitian ini adalah dapat digunakan sebagai informasi awal bagi pengambil kebijakan dalam mengelola dan mengatur pemanfaatan lahan pada DAS Prafi.

METODE PENELITIAN

Kondisi Umum Lokasi Penelitian
Penelitian dilaksanakan pada bulan Mei 2013 pada lokasi DAS Prafi Kabupaten Manokwari. Lokasi ini dipilih karena merupakan salah satu DAS dari empat buah DAS yang yang berada dalam Propinsi Papua Barat yang termasuk dalam kategori DAS Prioritas.

Untuk menduga besarnya erosi digunakan metoda overlay yaitu beberapa peta transparan (peta tanah, peta topografi/kelerengan dan peta tataguna lahan) saling ditumpang susun satu dengan yang lain. Prosedur penelitian meliputi pengumpulan data/survey lapangan dan analisis laboratories. Pengumpulan data berupa data primer dan data sekunder. Data primer berupa pengambilan contoh tanah di lapangan, sedangkan data sekunder berupa data curah hujan yang diperoleh dari Stasiun Klimatologi yang terdekat dengan DAS Prafi, serta keadaan umum daerah penelitian dari instasi terkait. Analisis laboratories yaitu analisis tanah dilaksanakan di laboratorium tanah Fakultas Pertanian dan Teknologi Hasil Pertanian Universitas Papua Manokwari, meliputi tekstur, struktur, kandungan bahan organic, dan permeabilitas tanah.

\section{Analisis Data}

Dalam penelitian beberapa analisis dilakukan antara lain: analisis indeks erosivitas hujan (EI30). Erosivitas hujan adalah kekuatan hujan yang menimbulkan erosi pada lahan yang tidak dilindungi. Karena data yang diperoleh adalah data curah hujan bulanan, maka untuk data erosivitas Hujan (EI30), dianalisis dengan menggunakan persamaan sebagai berikut (Asdak 1995):

$$
\mathrm{EI}_{30}=2,21 . \mathrm{R} 1.36
$$


dimana:

$\mathrm{EI}_{30}=$ Indeks erosivitas hujan (ton.m/ha.jam)

$\mathrm{R}=$ Curah hujan bulanan $(\mathrm{cm})$.

Selain itu, dianalisis juga erodibilitas ditentukan dengan menggunakan nomograf untuk menentukan faktor erodibilitas tanah yang ditetapkan berdasarkan sifat fisik tanah. Analisis faktor panjang dan kemiringan lereng (LS) dilakukan juga guna mengetahui perbandingan tanah yang hilang pada panjang lereng tertentu terhadap erosi yang terjadi pada panjang lereng baku 22 meter pada kemiringan 9\%. Untuk menduga nilai faktor lereng (LS), Wischmeier dan Smith (1978) mengemukakan suatu rumus yaitu:

$$
L S=\sqrt{\frac{L(0,136+0,0975 \mathrm{~S}+0,0139 \mathrm{~S} 2)}{100}}
$$

Dimana:

$\mathrm{L}=$ Panjang lereng $(\mathrm{m})$ yang diukur dari tempat mulai terjadinya aliran air di atas permukaan tanah sampai tempat mulai terjadi pengendapan.

$\mathrm{S}=$ Kemiringan lereng (\%).

\section{Sementara untuk pendugaan erosi,}

analisis dilakukan melalui mendugaan persamaan yang dikembangkan oleh Wischmeier dan Smith (1978):

$\mathrm{A}=\mathrm{R} \times \mathrm{K} \times \mathrm{LS} \times \mathrm{C} \times \mathrm{P}$

Dimana:

$\begin{array}{ll}\mathrm{A} & =\text { Erosi Aktual (ton/ha/tahun) } \\ \mathrm{R} & =\text { Indeks erosivitas hujan } \\ \mathrm{K} & =\text { Faktor erodibilitas tanah } \\ \mathrm{LS} & =\text { Indeks panjang dan kemiringan } \\ & \text { lereng } \\ \mathrm{C} & =\text { Faktor tanaman } \\ \mathrm{P} & =\text { Faktor teknik konservasi tanah. }\end{array}$

\section{HASIL DAN PEMBAHASAN}

\section{Hasil}

Dari hasil pengamatan di lapangan DAS Prafi yang berada pada Distrik Menyambow merupakan daerah yang berbukit-bukit, dengan kondisi kelerengan curam sampai sangat curam. Keadaan hutan pada daerah hulu dalam kondisi yang masih bagus hal ini ditandai dengan masih terdapat empat sampai lima strata vegetasi dalam hutan tersebut, daerah-daerah yang pernah terbuka ditandai dengan tumbuhnya semak belukar serta hutan campuran, namun karena kelerengan yang curam membuat daerah ini rentan terhadap erosi, umumnya erosi yang terjadi adalah erosi alur, erosi tebing sungai, erosi lapik, dan erosi mercu.

Pada daerah-daerah tertentu sering dijumpai tanaman kebun rakyat yang sengaja dibuka oleh masyarakat setempat menjadi areal perkebunan mereka, dibeberapa areal yang sengaja dibuka oleh masyarakat sebagai kebun kemudian dijadikan sebagai lokasi pengamatan. Dari beberapa tempat di area DAS Prafi telah dilakukan pengamatan pada beberapa lokasi (spot pengamatan) untuk menduga besarnya erosi yang terjadi pada DAS Prafi.

\section{Indeks Erosivitas Hujan (EI30)}

Data curah hujan yang dipakai untuk analisis karakteristik adalah data curah hujan yang diperoleh dari Badan Meteorologi Klimatologi dan Geofisika (BMKG) Wilayah V Stasiun Meteorologi Klas III Rendani Manokwari. Penentuan nilai erosivitas hujan (EI30) pada DAS Prafi dilakukan dengan menggunakan data curah hujan bulanan selama 5 (lima) tahun dari tahun 2007 - 2011. Hasil perhitungan menunjukkan bahwa rata-rata 
curah hujan maksimum terjadi pada bulan Maret $(265,20 \mathrm{~mm})$ dan rata-rata curah hujan minimum terjadi pada bulan Oktober $(101,88 \mathrm{~mm})$. Indeks Erosivitas Hujan (EI30) maksimum terjadi pada bulan Maret (190,74 ton.m/ha.jam), sedangkan EI30 minimum terjadi pada bulan Oktober (51,93 ton.m/ha.jam).

\section{Kepekaan Tanah (K)}

Data kepekaan tanah diperoleh dari analisis laboratorim dari kelima sampel tanah yang berasal dari spot pengamatan, sampel-sampel tersebut kemudian dianalisis untuk mengetahui sifat fisik (tekstur, struktur dan permeabilitas tanah) dan kandungan bahan organik tanah.

Tabel 1. Sifat fisik dan bahan organik tanah serta indeks kepekaan tanah terhadap erosi dari 12 lokasi pengamatan di DAS Prafi.

\begin{tabular}{|c|c|c|c|c|c|c|c|c|}
\hline \multirow{2}{*}{$\begin{array}{c}\text { Kelompok } \\
\text { Lokasi }\end{array}$} & \multicolumn{3}{|c|}{ Kelas Tekstur } & \multirow{2}{*}{$\begin{array}{l}\mathrm{BO} \\
(\%)\end{array}$} & \multirow{2}{*}{$\begin{array}{c}\text { Kelas } \\
\text { Tekstur }\end{array}$} & \multirow{2}{*}{$\begin{array}{c}\text { Kelas } \\
\text { Struktur }\end{array}$} & \multirow[t]{2}{*}{ Permeabilitas } & \multirow[t]{2}{*}{$\overline{\mathrm{K}}$} \\
\hline & $\begin{array}{c}\text { Pasir } \\
(\%)\end{array}$ & $\begin{array}{l}\text { Liat } \\
(\%)\end{array}$ & $\begin{array}{c}\text { Debu } \\
(\%)\end{array}$ & & & & & \\
\hline 1,2 & 40 & 21 & 39 & 1,26 & Lempung & $\begin{array}{l}\text { Gumpal } \\
\text { Membulat }\end{array}$ & Lambat & 0,23 \\
\hline 3,4 & 37 & 30 & 33 & 0,8 & $\begin{array}{l}\text { Lempung } \\
\text { Berliat }\end{array}$ & $\begin{array}{l}\text { Gumpal } \\
\text { Bersudut }\end{array}$ & $\begin{array}{l}\text { Sangat } \\
\text { Lambat }\end{array}$ & 0,43 \\
\hline $5,6,7$ & 54 & 25 & 21 & 2,52 & $\begin{array}{l}\text { Lempung } \\
\text { Berliat }\end{array}$ & $\begin{array}{l}\text { Gumpal } \\
\text { Membulat }\end{array}$ & Lambat & 0,28 \\
\hline 8,9 & 48 & 26 & 26 & 2,65 & $\begin{array}{l}\text { Lempung } \\
\text { Berliat }\end{array}$ & $\begin{array}{l}\text { Gumpal } \\
\text { Membulat }\end{array}$ & Sedang & 0,14 \\
\hline $10,11,12$ & 32 & 21 & 47 & 2,93 & $\begin{array}{l}\text { Lempung } \\
\text { Berliat }\end{array}$ & Massif & Lambat & 0,20 \\
\hline
\end{tabular}

Untuk mengetahui indeks kepekaan tanah (K) terhadap erosi maka hasil analisis laboratorium sifat fisik tanah dan bahan organik dari kelima sampel tanah tersebut kemudian dianalisis menggunakan nomograph. Hasil analisis kepekaan tanah terhadap erosi berdasarkan nomograph dapat dilihat pada Tabel 1.

Tabel 2. Panjang lereng (L) dan kemiringan lereng (S) serta nilai LS dari 12 lokasi pengamatan di DAS Prafi.

\begin{tabular}{lccc}
\hline \multicolumn{1}{c}{$\begin{array}{c}\text { Kelompok } \\
\text { Lokasi }\end{array}$} & $\begin{array}{c}\text { Panjang } \\
\text { Lereng }(\mathrm{m})\end{array}$ & $\begin{array}{c}\text { Kemiringan } \\
(\%)\end{array}$ & Nilai LS \\
\hline $2,7,9,12$ & 25 & 5 & 0,40 \\
$3,5,10$ & 25 & 45 & 16,21 \\
$1,4,6,8,11$ & 25 & 30 & 7,73 \\
\hline
\end{tabular}

18

@ Asosiasi Peneliti Biodiversitas Papuasia - Fakultas Kehutanan UNIPA
Berdasarkan indeks kepekaan tanah terhadap erosi pada Tabel 1, maka lokasi $8,9,10,11$ dan 12 memiliki kepekaan yang rendah terhadap erosi, sedangkan lokasi 1, 2, 5, 6, dan 7 memiliki kepekaan yang sedang terhadap erosi, indeks kepekaan erosi agak tinggi berada pada $\begin{array}{llll}\text { lokasi } & 3 & \text { dan } & \end{array}$ 
Panjang dan Kemiringan Lereng (LS)

Nilai LS dari masing-masing lokasi pengamatan ditentukan dengan menggunakan persamaan perhitungan untuk mengetahui nilai LS. Nilai ini dapat pula ditentukan dengan menggunakan nilai LS yang sudah ada. Panjang lereng (L) dan kemiringan lereng (S) dari setiap lokasi pengamatan dan nilai LS dari lokasi-lokasi tersebut tersaji dalam Tabel 2 .

Dari hasil penelitian yang diperoleh pada lokasi penelitian, terdapat ukuran nilai kemiringan lereng (LS) berdasarkan jenis tanah yaitu:

a. Pada daerah 2, 7, 9, dan 12 dengan jenis tanah Compex Podsolik memiliki kemiringan lereng $0-8 \%$, nilai $\mathrm{LS}$ adalah 0,4 dan daerah $1,4,6$, 8, dan 11 memiliki kemiringan $25-$ $40 \%$ nilai $\mathrm{LS}$ adalah 7,73 .

b. Pada daerah 1, 4, 6, 8 dan 11 dengan jenis tanah Latosol memiliki kemiringan lereng $25-40 \%$, nilai LS adalah 7,73 dan daerah 3,5 dan 10 kemiringan $>40 \%$ nilai LS adalah 16,21 .

Tabel 3. Nilai faktor $\mathrm{C}$ untuk beberapa jenis tanaman penutup tanah

\begin{tabular}{lll}
\hline No. & \multicolumn{1}{c}{ Faktor C } & Nilai C \\
\hline 1. & Kebun Campuran & 0,43 \\
2. & Perkebunan Kelapa Sawit & 0,50 \\
3. & Hutan Lahan Kering Primer & 0,001 \\
4. & Hutan Lahan Kering Sekunder & 0,01 \\
5. & Semak Belukar & 0,01 \\
6. & Pemukiman & 1,0 \\
\hline
\end{tabular}

\section{PEMBAHASAN}

Erosi merupakan salah satu bentuk kerusakan tanah sebagai akibat hilangnya lapisan oleh tanah (top soil). Hilangnya c. Pada daerah $2,7,9$, dan 12 dengan jenis tanah Red Yellow Podsolik memiliki kemiringan lereng $0-8 \%$, nilai LS adalah 0,4 dan daerah $1,4,6$, 8, dan 11 kemiringan $25-40 \%$ dengan nilai LS adalah 7,73.

\section{Vegetasi}

Secara umum vegetasi dikatakan dapat mencegah erosi tetapi pengaruh setiap jenis tanaman atau vegetasi terhadap erosi berbeda. Jenis-jenis vegetasi pada lokasi yang dijadikan sebagai spot pengamatan untuk menduga besarnya erosi adalah area semak belukar, perkebunan kelapa sawit, kebun campuran dan tanaman semusim, hutan lahan kering primer, hutan lahan kering sekunder. Untuk kebun campuran umumnya ditanami dengan pisang, cabe, papaya serta jagung, sedangkan pada lokasi yang lain hanya ditanami dengan satu jenis tanaman saja yaitu wortel, kentang, daun bawang, kubis dan tomat. Nilai faktor $\mathrm{C}$ ditentukan dengan menggunakan Tabel Nilai $C$ seperti yang disajikan dalam Tabel 3.

lapisan oleh tanah ini diakibatkan oleh kegiatan dispersi dan pengangkutan tanah dari satu tempat ke tempat lain oleh air hujan yang mengalir dipermukaan. Menurut Kesaulija (1982), terdapat 2 (dua) terminologi berdasarkan proses 
erosi yaitu erosi potensial dan erosi aktual.

\section{Erosi Potensial}

Untuk menentukan cara-cara pengelolaan lahan yang sesuai dan tepat di suatu wilayah perlu diketahui besarnya erosi potensial. Erosi potensial adalah erosi yang terjadi pada lahan yang terbuka tanpa vegetasi dan tanpa campur tangan manusia. Banyaknya erosi potensial merupakan angka maksimum dari erosi yang terjadi pada daerah tersebut.

Tabel 4. Pendugaan jumlah erosi aktual pada areal pengamatan di DAS Prafi

\begin{tabular}{|c|c|c|c|c|c|}
\hline \multirow[t]{2}{*}{ No. } & \multirow{2}{*}{$\begin{array}{l}\text { Unit } \\
\text { Lahan }\end{array}$} & \multirow{2}{*}{$\begin{array}{c}\text { Tipe } \\
\text { Penggunaan Lahan }\end{array}$} & \multirow[t]{2}{*}{$\mathrm{CP}$} & \multicolumn{2}{|c|}{ Erosi } \\
\hline & & & & $\begin{array}{c}\text { Potensial } \\
\text { Ton/ha/thn }\end{array}$ & $\begin{array}{c}\text { Aktual } \\
\text { Ton/ha/thn }\end{array}$ \\
\hline 1. & RK1LS2 & Kebun Campuran & 0.43 & $2,128.04$ & 915.06 \\
\hline \multirow[t]{3}{*}{2.} & RK1LS1 & Pemukiman & 1.00 & 110.12 & 110.12 \\
\hline & & Perkebunan (Kelapa Sawit) & 0.50 & & 55.06 \\
\hline & & Hutan Lahan Kering Sekunder & 0.01 & & 1.10 \\
\hline \multirow[t]{2}{*}{3.} & RK2LS3 & Hutan Lahan Kering Sekunder & 0.01 & $8,343.04$ & 83.43 \\
\hline & & Hutan Lahan Kering Primer & 0.001 & & 8.34 \\
\hline \multirow[t]{2}{*}{4.} & RK2LS2 & Hutan Lahan Kering Sekunder & 0.01 & $3,978.51$ & 39.79 \\
\hline & & Hutan Lahan Kering Primer & 0.001 & & 3.98 \\
\hline 5. & RK3LS3 & Hutan Lahan Kering Primer & 0.001 & $5,432.68$ & 5.43 \\
\hline 6. & RK3LS2 & Hutan Lahan Kering Primer & 0.001 & $2,590.66$ & 2.59 \\
\hline 7. & RK3LS1 & Hutan Lahan Kering Sekunder & 0.01 & 134.06 & 1.34 \\
\hline \multirow[t]{2}{*}{8.} & RK4LS2 & Hutan Lahan Kering Sekunder & 0.01 & $1,295.33$ & 12.95 \\
\hline & & Kebun Campuran & 0.43 & & 556.99 \\
\hline \multirow[t]{4}{*}{9.} & RK4LS1 & Hutan Lahan Kering Primer & 0.001 & 67.03 & 0.07 \\
\hline & & Pemukiman & 1.00 & & 67.03 \\
\hline & & Kebun Campuran & 0.43 & & 28.82 \\
\hline & & Perkebunan (Kelapa Sawit) & 0.50 & & 33.52 \\
\hline \multirow[t]{2}{*}{10.} & RK5LS3 & Hutan Lahan Kering Primer & 0.001 & $3,880.48$ & 3.88 \\
\hline & & Semak Belukar & 0.01 & & 38.80 \\
\hline \multirow[t]{2}{*}{11.} & RK5LS2 & Hutan Lahan Kering Sekunder & 0.01 & $3,673.13$ & 36.73 \\
\hline & & Hutan Lahan Kering Primer & 0.001 & & 3.67 \\
\hline \multirow[t]{2}{*}{12.} & RK5LS1 & Pemukiman & 1.00 & 95.76 & 95.76 \\
\hline & & Perkebunan (Kelapa Sawit) & 0.50 & & 47.88 \\
\hline
\end{tabular}

Dengan menggunakan persamaan USLE maka erosi potensial yang terjadi pada masing-masing lokasi pengamatan. Dari hasil pendugaan erosi potensial yang terjadi di lokasi penelitian menunjukkan jumlah kehilangan tanah berkisar antara $67,03-8.343,04$ ton/ha/tahun. Tingginya erosi potensial pada kawasan daerah aliran sungai Prafi ini disebabkan selain curah hujan yang cukup tinggi, juga daerah dengan tingkat kemiringan lereng yang tinggi. Penyebab lain adalah jenis tanah dengan struktur tanah yang mengandung pasir, kurangnya ketersediaan bahan organik, permeabilitas tanah sedang sampai sangat lambat. 


\section{Erosi Aktual}

Erosi Aktual yang dimaksud disini adalah dugaan besarnya erosi yang terjadi untuk pola tata guna lahan sekarang (present land use) dan cara konservasi tanah yang dilaksanakan. Dari hasil perhitungan pendugaan jumlah erosi aktual tahunan diperoleh nilai-nilai seperti disajikan pada Tabel 4.

Hutan berperan melindungi tanah terhadap daya perusak butir-butir hujan yang jatuh, memperbaiki kapasitas infiltrasi tanah dan absorbsi air serta mengurangi daya perusak air yang mengalir di atas permukaan tanah. Hasil pendugaan erosi aktual yang terjadi pada hutan lahan kering primer sebesar 0,07 8,34 ton/ha/tahun. Sedangkan pada hutan lahan kering sekunder erosi yang terjadi sebesar 1,10 - 83,43 ton/ha/tahun. Hutan merupakan suatu masyarakat tetumbuhan yang didominasi oleh tanaman berkayu.

Hutan alam dengan struktur yang rumit dan berlapis berperan penting dalam mencegah terjadinya penghanyutan tanah. Dengan adanya serasah maka aktivitas dan populasi biologis meningkat sehingga tanah menjadi porous mengakibatkan kapasitas infiltrasi dari tanah menjadi besar. Ini akan mengakibatkan jumlah limpasan permukaan tanah yang menyebabkan terjadinya erosi semakin kecil.

Jumlah erosi yang terjadi pada lahan semak belukar sebesar 38,80 ton/ha/tahun. Areal semak belukar umumnya adalah bekas perladangan yang tidak diusahakan lagi. Pada umumnya hutan belukar dicirikan oleh vegetasi campuran yang terdiri dari jenis pohonpohonan, perdu dan semaksemak/ rumput-rumput (Hidayat 1999).

Pada lahan perkebunan besarnya erosi $33,52-55,06$ ton/ha/tahun. Jenis tanaman yang diusahakan adalah tanaman kelapa sawit. Besarnya jumlah erosi pada lahan perkebunan kelapa sawit disebabkan karena berkurangnya perlindungan tanah berupa serasah dari vegetasi yang melindungi permukaan tanah dari tetesan air hujan terobosan (Suryanto dan Wawan 2017).

Jumlah erosi yang terjadi pada lahan pertanian yang ditanami oleh jenis tanaman sayur-sayuran sebesar 28,82 915,06 ton/ha/tahun. Besarnya jumlah tanah yang terangkut pada lahan pertanian ini selain ditentukan oleh kepekaan tanah, tingkat kemiringan lereng, juga semakin berkurangnya perlindungan tanah oleh vegetasi tinggi menyebabkan makin banyak tanah yang terdispersi bersamaan dengan meningkatnya limpasan permukaan (Bachtiar dan Ura 2017). Tingginya erosi aktual disebabkan karena kesalahan di dalam pengelolaan penggunaan lahan.

\section{Erosi Yang diperbolehkan}

Dari segi daya dukung tanah terhadap suatu pertumbuhan yang baik, erosi yang masih dapat dibiarkan adalah jumlah erosi yang seimbang dengan besarnya pembentukan tanah. Dari nilai-nilai hasil analisis dugaan erosi berdasarkan model persamaan USLE dan dengan mempertimbangkan nilai-nilai erosi yang masih dapat dibiarkan, maka dapat dikemukakan bahwa erosi yang terjadi pada keadaan tataguna lahan, kebun campuran, pemukiman, perkebunan kelapa sawit, hutan lahan kering sekunder pada DAS Prafi saat ini telah melampaui batas erosi yang masih dapat dibiarkan.

\section{DAFTAR PUSTAKA}

Asdak, C. 1995. Hidrologi dan Pengelolaan Daerah Aliran Sungai. 
Gadjah Mada University Press. Yogyakarta.

Bachtiar B dan Ura R. 2017. Pengaruh tegakan Lamtoro gung Leucaena leucocephala L. terhadap kesuburan tanah dikawasan hutan Ko'mara Kabupaten Takalar. Jurnal Ilmu Alam dan Lingkungan Vol 8 (15): 1-6.

Fuady Z dan Azizah C. 2008. Tinjauan daerah aliran sungai sebagai sistem ekologi dan manajemen daerah aliran sungai. Lentera, Vol 6: 1-10.

Hidayat S. 1999. Tipe-tipe vegetasi di kawasan Sumba Timur dan tantangan konservasinya. Prosiding Seminar Hasil-Hasil Penelitian Bidang Ilmu Hayati. Pusat Antar Universitas Ilmu Hayati IPB, Bogor.

Kesaulija, E. M. 1982. Analysis of Hydro-orological System at the Ajibaru Basin, Upper Way Seputih Watershed. Lampung. Ersosion and Sedimentation. SEAMEO Biotrop. Bogor.
Laturua A, Hendrayanto dan Puspaningsih N. 2018. Penggunaan lahan optimal dalam tranformasi hujan limpasan di DAS Wae Ruhu. Media Konservasi Vol 23(1): 52-64.

Muharomah R. 2014. Analisis run-off sebagai dampak perubahan lahan sekitar pembangunan underpass Simpang Patal Palembang dengan memanfaatkan teknik GIS. Jurnal Teknis Sipil dan Lingkungan, Vol 2 (3): 424-433.

Suryanto dan Wawan. 2017. Pengaruh kemiringan lahan dan Mucuna bracteata terhadap aliran permukaan dan erosi PT. Perkebunan Nusantara V Kebun Lubuk Dalam. JOM Faperta Vol 4 (1): 1-15.

Wischmeir WH, and Smith DD. 1978. Predicting rainfall erosion losses $-\mathrm{a}$ guide to conservation planning. U.S. Department of Agriculture, Agriculture Handbook No. 537.

Wuryanti A dan Susanti PD. 2015. Analisis spasial teknik pendugaan terhadap lahan pertanian di sub DAS Keduang, Kabupaten Wonogiri, Jawa Tengah. Jurnal Penelitian Sosial dan Ekonomi Kehutanan Vol 12 (3): 149162. 